\title{
APERFEIÇOAMENTO DA TÉCNICA DE ELETROFORESE PARA ANÁLISE ISOENZIMÁTICA DE CLONES DE SERINGUEIRA (Hevea sp. $)^{1}$
}

\author{
Antonio N. KALIL FILHO ${ }^{2}$, Marco Antonio D. LAMA ${ }^{3}$, Moacyr A. MESTRINER ${ }^{4}$
}

RESUMO - Este estudo foi conduzido no sentido de otimizar as técnicas de preparo de extratos de foliolos e identificar tampões e condições de corrida que proporcionassem uma boa definição dos perfis eletroforéticos de clones de seringueira. Foram testados 25 diferentes sistemas enzimáticos utilizando-se onze sistemas tamponantes. Nào foram encontradas diferenças na qualidade dos zimogramas obtidos nos diferentes estádios fenológicos analisados, em amostras submetidas a diferentes condições de centrifugação e nas diferentes plantas de um mesmo clone. Extratos de foliolos liofilizados apresentaram resolução semelhante para Adh, Pgi, 6Pgdh, Lap-1, Skdh, Acp, Mdh, BGlu, Pgm e ldh que homogenados de folíolos não liofilizados preparados até 2 dias pós-coleta. Os padrões de Got e Est apresentaram boa nitidez somente em extratos de foliolos frescos. As demais enzimas não apresentaram resolução satisfatória. Com o uso de diferentes substratos, foi possivel detectar nove regiões de atividade esterásica nas condições empregadas, embora variação genética tenha sido caracterizada para apenas três locos nos clones analisados. Os fenótipos observados para esterase7 utilizando-se ésteres derivados de naftol foram semelhantes aos padrões encontrados utilizando L-benzoil- $\beta$ naftilamida como substrato, indicando que esta esterase seja, provavelmente, uma endopeptidase. A utilização de substratos fluorogênicos permitiu ainda a detecção de uma variante eletroforética de Acp em Hevea nitida e uma variante de $\beta$ Glu em Hevea rigidifolia.

Palavras-chave: seringueira, clones, eletroforese, isoenzimas.

\section{Development of Electrophoresis Technique for Isoenzymatic Analysis of Rubber Tree} (Hevea sp.) Clones.

ABSTRACT - This study aimed at optimizing techniques for preparing clonal leaflet extracts and identifying buffers and migration conditions so as to achieve better resolution of electrophoretic patterns in rubber tree clones. Twenty-five enzymatic systems in eleven gel and electrode buffers were tested. Similar electrophoretic profiles were obtained from extracts of clones in different phenological stages, in samples submitted to different centrifugation conditions and in plants from the same clone. Extracts from liophylized leaflets showed the same electrophoretic resolution as nonliophylized leaflets after two days for Adh, Pgi, 6Pgdh, Lap-I, Skd, Acp, Mdh-1, $\beta$-Glu, Pgm and Idh. Got and Est electrophoretic patterns were well resolved only in fresh leaflets extracts. The other enzymes studied did not show a good electrophoretic resolution. Employing different types of substrates, nine regions of esterase activity were observed under the conditions used, although genetic variation has been characterized for only three loci in the clones analysed. Est-7 phenotypes observed using naphtyl-esters were similar to patterns found using L-benzoyl$\beta$-naphtylamide assubstrate, suggesting that this esterase is an endopeptidase. The use of fluorogenic substrates allows the detection of a new electrophoretic Acp variant in Hevea nitida and another $\beta$ Glu variant in Hevea rigidifolia leaflet extracts.

Key words: rubber tree, clones, electrophoresis, isoenzymes

1 Parte da Tese apresentada por ANKF ao Departamento de Genética e Matemática Aplicada à Biologia, FMRP, USP, Ribeirão Preto, para a obtenção do título de Doutor.

2 Centro de Pesquisa Agroflorestal da Amazônia Ocidental (CPAA), Empresa Brasileira de Pesquisa Agropecuária ( EMBRAPA), Caixa Postal 319, 69.048-660, Manaus, AM, Brasil.

3 Departamento de Genética e Evolução, Universidade Federal de São Carlos, Caixa Postal 676, 013565-905, São Carlos, SP, Brasil.

4 Departamento de Genética, Faculdade de Medicina de Ribeirão Preto, Av. Bandeirantes n 3.900, 14049-900, Ribeirão Preto, SP, Brasil. 


\section{INTRODUÇÃO}

A seringueira, planta oriunda da Região Amazônica, produz o látex, matéria-prima para a obtenção da borracha natural, utilizada na fabricação de pneus radiais e instrumentos cirúrgicos, entre outras utilidades (Dean, 1989).

Dada à sua importância estratégica, os paises membros do IRRDB (International Rubber Research Development Board) realizaram, em 1981, uma prospecção e coleta de germoplasma de populações naturais de Hevea brasiliensis na Amazônia Ocidental, nos estados do Acre, Rondônia e Mato Grosso, visando à ampliação da base genética do material Wickham existente na Ásia e África.

A partir deste material, foi feita a primeira caracterização isoenzimática em folhas de seringueira (IRCA,1981). Esta caracterização objetivou determinar a variabilidade do material amazônico, comparando-a com a do material Wickham, já domesticado na Ásia, verificando-se, assim, se a variabilidade genética destes clones estaria esgotada frente à constante manipulação por seleção. Foram analisados vinte e cinco sistemas enzimáticos, doze dos quais exibiram boa resolução: Mdh, Skdh, Lap, Est, Pgi, Got, Sod, $\beta$ Glu, Acp, Adh, Idh e 6Pgdh.

Posteriormente, Soleille (1984) realizou estudos sobre o determinismo genético de alguns sistemas isoenzimáticos de Hevea brasiliensis. A partir dos fenótipos encontrados, a autora estabeleceu a base genética dos padrões isoenzimáticos de Got, Lap, Est, Acp e Sod.

A estes estudos iniciais, seguiramse outros na tentativa de quantificar a variabilidade genética de populações de Hevea. Amostras de $H$. brasiliensis do Acre, Rondônia e Mato Grosso, ao serem analisadas, apresentaram $33 \%$ de sua variabilidade entre estados; $93 \%$ da variabilidade era expressa dentro de cada distrito e somente $7 \%$ representava a variabilidade interdistrito (Chevallier, 1984; Chevallier et al., 1985). Chevallier (1988) detectou 59 alelos em 20 locos amostrados, um dos quais monomórfico, no material da prospecção de 1981 na Amazônia (Mato Grosso, Acre e Rondônia), encontrando 18 locos e 36 alelos nos clones Wickham, com cinco locos monomórficos. A maior porcentagem de locos polimórficos foi exibida pelo material de Mato Grosso (97\%), seguida pelo Acre $(82,5 \%)$ e Rondônia (73,3\%). A menor porcentagem de alelos raros foi encontrada em Hevea proveniente do Mato Grosso (23\%) contra $41 \%$ e $34 \%$ do Acre e Rondônia, respectivamente. Foi observada ainda forte heterogeneidade geográfica nas frequências alélicas, detectando-se correlação positiva entre sete alelos e longitude. A heterozigosidade média total alcançou 0,418 no germoplasma nativo e 0,362 na coleção Wickham.

Os trabalhos mencionados, entretanto, não fornecem informações detalhadas quanto à metodologia empregada para a obtenção de padrões eletroforéticos satisfatórios para um grande número de enzimas, dificultando a tarefa dos que se utilizam da técnica eletroforética para estudos de marcadores genéticos no gênero Hevea. Este trabalho se propôs a testar técnicas de preparo de extratos de foliolos de seringueira e diferentes tampões, bem como substratos não 
usualmente empregados, com o objetivo de padronizar condições que permitissem uma melhor definição dos perfis eletroforéticos, tornando possivel ainda a detecção de novas variantes eletroforéticas.

\section{MATERIAL E MÉTODOS}

O material de estudo constou de foliolos coletados nos estádios fenológicos $\mathrm{B}_{2}, \mathrm{~B}_{3}$ e $\mathrm{C}$ (Hallé et al., 1978) no Campo Experimental do Centro de Pesquisa Agroflorestal da Amazônia Ocidental (CPAA), em Manaus, e na Escola Superior de Agricultura "Luiz de Queiroz" (ESALQ/USP), Piracicaba, SP. Foram coletados cinco folíolos de três plantas de cada um dos seguintes clones: IAN 717, Fx 3899, IAN 873, LCB 510, PB 86, IAN 2909 e Fx 3864.

Os foliolos foram imediatamente liofilizados a $-52^{\circ} \mathrm{C}$ sob pressão de 0,1 mbar por 72 horas. Extratos de folíolos frescos ou liofilizados foram preparados utilizando-se o tampão tris-cisteína $\mathrm{pH}$ 7.4 (Lebrun \& Chevallier, 1988) na proporção de $110 \mathrm{mg}$ (foliolos frescos) ou $33 \mathrm{mg}$ (foliolos liofilizados) para 1 $\mathrm{ml}$ do tampão. Os folíolos foram macerados sob baixa temperatura em cadinho de porcelana na presença de 35 mg de polivinil pirrolidona (PVP) e os homogenados obtidos foram submetidos à centrifugação ou por $25 \mathrm{~min}$ a $15000 \mathrm{~g}$, à $4^{\circ} \mathrm{C}$, ou a $2500 \mathrm{~g}$ por 15 minutos, à temperatura ambiente. Os géis de amido (Sigma) foram preparados a $12 \%$; os tampões do gel e do eletrodo, bem como as condições de migração estão apresentados na Tabela 1. Os géis foram submetidos à corrida eletroforética por 5 horas, exceto para o tampão 4 (4 horas). Misturas de reação descritas por Harris \& Hopkinson (1976), Lebrun \& Chevallier (1988) e Alfenas et al. (1991) foram utilizadas para detecção da atividade de 25 sistemas enzimáticos: álcool desidrogenase (Adh), amilase ( $\alpha-A m)$, catalase (Cat), endopeptidases (Enp), enzima málica (Me), esterases (Est), fosfatase ácida (Acp), fosfatase alcalina (Alp),

Tabela 1. Sistemas-tampão do gel e dos eletrodos e condições de migração utilizados para análise eletroforética de diferentes sistemas enzimáticos em extratos de foliolos de seringueira (Hevea sp).

\begin{tabular}{|c|c|c|c|}
\hline $\mathrm{Ne}^{2}$ & Tampão do eletrodo & Tampão do gel & Condição A-V/cm \\
\hline 1 & tris $0,15 \mathrm{M}+$ ác. citrico $0,05 \mathrm{M} \mathrm{pH} \mathrm{6,6}$ & histidina $5 \mathrm{mM}$ pH 6,0 & $1,5 \mathrm{~mA}$ \\
\hline 2 & tris $0,1 \mathrm{M}+$ ác. cítrico $0.028 \mathrm{M} \mathrm{pH} 7,5$ & diluiçäo $8 x$ & $1.5 \mathrm{~mA}$ \\
\hline 3 & $\begin{array}{l}\text { tris } 0,1 \mathrm{M}+\text { anidrido malêico } 0,1 \mathrm{M}+ \\
\text { EDTA } 0,01 \mathrm{M}+\mathrm{MgCl}_{2} 0,01 \mathrm{M}\end{array}$ & diluição 10x & $10 \mathrm{~V}$ \\
\hline 4 & tris $0,15 \mathrm{M}+$ ác. cítrico $0,05 \mathrm{M} \mathrm{pH} 6,6$ & histidina $34 \mathrm{mM} \mathrm{pH} 8,0$ & $1,5 \mathrm{~mA}$ \\
\hline 5 & $\begin{array}{l}\mathrm{NaH}_{2} \mathrm{PO}_{4} 0,1 \mathrm{M}+\mathrm{Na}_{2} \mathrm{HPO}_{4} 0,1 \mathrm{M}+ \\
\text { EDTA } 1 \mathrm{mM}+\mathrm{MgCl}_{2} 1 \mathrm{mM} \mathrm{pH} 6,7\end{array}$ & diluiçāo $15 x$ & $10 \mathrm{~V}$ \\
\hline 6 & citrato sódio $0,41 \mathrm{M} \mathrm{pH} \mathrm{6,0}$ & histidina $5 \mathrm{mM}$ pH 6,0 & $10 \mathrm{~V}$ \\
\hline 7 & tris $0,25 \mathrm{M}+$ ác. citrico $0,057 \mathrm{M} \mathrm{pH} 8,0$ & tris $17 \mathrm{mM}+$ ác. citrico $23 \mathrm{mM}$ pH 8,0 & $1.5 \mathrm{~mA}$ \\
\hline 8 & borato $0,3 \mathrm{M} \mathrm{pH} 8,3$ & tris $17 \mathrm{mM}+$ ác. citrico $23 \mathrm{mM} \mathrm{pH} 8,0$ & $1,5 \mathrm{~mA}$ \\
\hline 9 & tris $0,135 \mathrm{M}+$ ác. citrico $0,043 \mathrm{M} \mathrm{pH} 7,0$ & tris $90 \mathrm{mM}+$ ác. cítrico $30 \mathrm{mM} \mathrm{pH} 7,0$ & $10 \mathrm{~V}$ \\
\hline 10 & borato $0,3 \mathrm{M} \mathrm{pH} 8,3$ & tris $0,19 \mathrm{M}+$ ác. cítrico $0,024 \mathrm{M} \mathrm{pH} \mathrm{7,2}$ & $10 \mathrm{~V}$ \\
\hline 11 & fosfato sódio $0,1 \mathrm{M} \mathrm{pH} 6,5$ & diluição $10 x$ & $10 \mathrm{~V}$ \\
\hline
\end{tabular}


fosfoglucomutase (Pgm), 6-fosfogluconato desidrogenase (6Pgdh), fosfohexoseisomerase (Pgi), $\alpha$-glicerofosfato desidrogenase ( $\alpha$-Gpdh), $\beta$-glucosidade $(\beta$-Glu), transaminase glutâmicaoxaloacética (Got), transaminase glutâmica-pirúvica (Gpt), hexoquinase (Hk), isocitrato desidrogenase (Idh), leucil-aminopeptidase (Lap), malato desidrogenase $(\mathrm{Mdh})$, peroxidases $(\mathrm{Po})$, pirofosfatases $(\mathrm{Pp})$, polifenoloxidases (Ppo), shikimato desidrogenase (Skdh), sorbitol desidrogenase (Sdh) e superóxido dismutase (Sod) (ver Tab. 2).

A detecção da atividade de algumas enzimas foi realizada utilizando-se diversos substratos. A atividade esterásica foi visualizada através de ésteres fluorogênicos (acetato, butirato, propionato e palmitato de 4-metil umbeliferona ou diacetato de fluoresceína) e de derivados de $\alpha$-e $\beta$-naftol (acetato, butirato e propionato). Para a detecção das peroxidases, foram utilizados os aceptores orto-dianisidina, 9 etil-carbazola e guaiacol. As polifenoloxidases foram visualizadas com o emprego de DLDOPA(DL-Dihidroxifenilalanina), catecol, metil-catecol e tirosina metil-éster.

Foram comparados os padrões eletroforéticos de extratos de foliolos

Tabela 2. Sistemas enzimáticos estudados eletroforeticamente em extratos de foliolos de seringueira; em negrito, está indicado o sistema-tampão que proporcionou a melhor resolução eletroforética das enzimas analisadas.

\begin{tabular}{|c|c|c|}
\hline Sistemas enzimáticos & № E.C. & Tampões \\
\hline Álcool desidrogenase - Adh & EC 1.1.1.1 & 1,4 \\
\hline$\alpha$-Amilase - $\alpha$-Am & EC 3.2.1.1. & 4 \\
\hline Catalase - Cat & EC 1.11.1.6 & 2 \\
\hline Endopeptidase - Enp & EC 3.4 & 3 \\
\hline Enzima málica - Me & EC 1.1.1.40 & 2 \\
\hline Esterase - Est & EC 3.1.1.1 & $1,2,4,5,8,11$ \\
\hline Fosfatase ácida - Acp & EC 3.1.3.2 & 1,2 \\
\hline Fosfatase alcalina - Alp & EC 3.1.3.1 & 2 \\
\hline Fosfoglicomutase - Pgm & EC 5.4.2.2 & 3,9 \\
\hline 6-Fosfogliconato desidrogenase - 6Pgdh & EC 1.1.1.44 & $2,5,9$ \\
\hline Fosfohexose isomerase - Pgi & EC 5.3.1.9 & 1,6 \\
\hline$\alpha$-Glicerofosfato desidrogenase - $\alpha$-Gpdh & EC 1.1.1.8 & 3 \\
\hline$\beta$-Glicosidase - $\beta$-Glu & EC 3.2.1.21 & 1,2 \\
\hline Transaminase glutâmica-oxaloacética - Got & EC 2.6.1.1 & $1,2,7,8$ \\
\hline Transaminase glutâmica-pirúvica - Gpt & EC 2.6.1.2 & 2 \\
\hline Hexoquinase - Hk & EC 2.7.1.1 & 3 \\
\hline Isocitrato desidrogenase - Idh & EC 1.1.1.42 & $2,5,9$ \\
\hline Leucil-aminopeptidase - Lap & EC 3.4.11.1 & $\mathbf{1 , 1 0}$ \\
\hline Malato desidrogenase - Mdh & EC 1.1.1.37 & 1,6 \\
\hline Peroxidase - Po & EC 1.11.1.7 & 2,4 \\
\hline Pirofosfatase -Pp & EC 3.6.1.1 & 2 \\
\hline Polifenoloxidase - Ppo & EC 1.14.18.1 & $1,2,3,4,11$ \\
\hline Shiquimato desidrogenase - Skdh & EC 1.1.1.25 & $1,2,5,9$ \\
\hline Sorbitol desidrogenase - Sdh & EC 1.1.1.14 & 2 \\
\hline Superóxido dismutase - Sod & EC 1.15.1.1 & 2,10 \\
\hline
\end{tabular}


não liofilizados, estocados $\mathrm{a}-20^{\circ} \mathrm{C}$ por tempo variável entre um a sete dias, com os de extratos de foliolos liofilizadosmantidos à mesma temperatura por dez meses para as enzimas Adh, Pgi, 6Pgdh, Lap-1, Skdh, Acp, Mdh, $\beta$-Glu, Pgm, Idh, Got e Est. Para todos os sistemas estudados, foram comparados os perfis de extratos de folíolos, liofilizados ou não, estocados por tempo variável entre 1 a 30 dias.

\section{RESULTADOS}

Dentre os vinte e cinco sistemas enzimáticos estudados, doze apresentaram excelente resolução: Acp, Adh, Est, $\beta$-Glu, Got, Idh, Lap-1, Mdh, 6Pgdh, Pgi, Pgm e Skdh. Os padrões isoenzimáticos referentes a $\mathrm{Adh}$, Idh, Pgi, Pgm e Skdh estão de acordo com os descritos na literatura e não merecerão comentários específicos. Novos achados em Acp, Est, $\beta$-Glu, Got, Lap-1, Mdh e 6Pgdh serão apresentados e discutidos a seguir. $\mathrm{O}$ determinismo genético destes sistemas isoenzimáticos, com os respectivos zimogramas ilustrativos dos padrões obtidos para cada um destes, está sendo detalhado em outro trabalho (Kalil Filho et al., submetido à publicação).

Não foi detectada atividade sobre o suporte eletroforético para as enzimas $\alpha$-Am, Cat, $\alpha$-Gpdh, Hk e $\mathrm{Sdh}$. Atividade para as demais enzimas ( $\alpha$ - e $\beta$-Alp, Gpt, Me, Pp, Po, Ppo e Sod) foi detectada e os resultados observados estão descritos abaixo.

A resolução dos zimogramas obtidos foi semelhante quando se comparou extratos de foliolos liofilizados ou frescos centrifugados a $4^{\circ}$
Cou à temperatura ambiente e em foliolos provenientes de clones em diferentes estádios fenológicos ( $B_{2}, B_{3}$ e $C$ ), bem como entre plantas de um mesmo clone.

Extratos de foliolos liofilizados e de foliolos frescos até dois dias póscoleta apresentaram padrões semelhantes e boa nitidez dos zimogramas para as enzimas Adh, Pgi, 6 Pgdh, Lap, Skdh, Acp, Mdh, $\beta$-Glu, Pgm e Idh. Contudo, Got e Est somente apresentaram resolução adequada em extratos de foliolos frescos até dois dias pós-coleta; extratos de folíolos liofilizados e estocados por vários meses não exibiram perfis eletroforéticos satisfatórios.

Extratos de foliolos, liofilizados ou não, estocados por mais de uma semana, não apresentaram zimogramas bem definidos para todas as enzimas estudadas.

Atividade peroxidásica foi revelada apenas utilizando odianisidina como aceptor. O padrão eletroforético das polifenoloxidases consistiu de uma região de atividade, sendo que L-DOPA parece ser o substrato mais adequado. Outras duas regiões de baixa atividade foram observadas, inclusive com a utilização de 4-metil catecol. A região de atividade peroxidásica parece corresponder à polifenoloxidase de maior intensidade.

Uma mesma região de baixa atividade foi detectada para $\alpha$-e $\beta$-Alp utilizando $\alpha$-e $\beta$-fosfato ácido de sódio; esta fração parece corresponder à fosfatase ácida (Acp) detectada com o emprego de fosfato de umbeliferona.

Baixa atividade sobre o suporte eletroforético foi observada para Me, Pp e Sod, dificultando melhor caracterização 
destas enzimas. Uma fraca região de atividade transaminásica glutâmicapirúvica (Gpt) foi detectada; esta região parece corresponder à Got-1 descrita abaixo.

Nove regiões de atividade esterásica foram detectadas, embora variação genética tenha sido caracterizada em apenas três locos esterásicos: $\underline{E s t}^{1}$, Est ${ }^{6}$ e Est ${ }^{7}$. As esterases $1,3,5$ e 9 foram reveladas com a utilização de ésteres derivados de naftol e com substratos fluorogênicos. As esterases 1,7 e 8 foram visualizadas somente através de ésteres derivados de naftol, enquanto que as esterases $2,4 \mathrm{e}$ 6 foram observadas apenas com o uso de substratos fluorogênicos. Estas diferentes regiões de atividade esterásica requerem o uso de tampões diferentes para uma resolução adequada.

Os padrões observados para a esterase-7 foram idênticos aos fenótipos verificados quando se utilizou o substrato L-benzoil $\beta$-naftilamida (BANA).

Três regiões de atividade da transaminase glutâmica-oxaloacética foram caracterizadas, geneticamente determinadas por locos distintos; variação genética foi observada nestas três regiões. Os produtos dos locos Got ${ }^{1}$ Got $^{2}$ e Got $^{3}$ foram melhor resolvidos sobre o suporte eletroforético com o uso dos sistemas-tamponantes 2 e 7 , respectivamente (ver Tab. 1).

Duas regiões de atividade leucilaminopeptidásica foram caracterizadas, produtos de dois locos distintos; entretanto, a região Lap-2 não apresentou resolução suficiente para permitir sua caracterização.

Os fenótipos observados de Mdh devem ser determinados por dois locos, um dos quais mostrou-se monomórfico $\left(\mathrm{Mdh}^{2}\right)$. O primeiro loco apresentou nos individuos presumivelmente heterozigotos um padrão de três bandas de maior mobilidade anódica, além de duas bandas de menor mobilidade. Nos homozigotos, o padrão apresentado era constituído de uma banda de maior mobilidade, além de uma banda mais lenta. Nos diferentes fenótipos heterozigóticos encontrados, as duas bandas correspondentes à região de menor mobilidade guardavam uma distância proporcional à posição das três bandas mais rápidas, evidenciando que as bandas mais lentas e as mais rápidas eram produtos do mesmo loco gênico. Semelhante achado foi verificado para a enzima 6 Pgdh.

Uma nova variante de Acp foi encontrada em $H$. nitida, bem como uma nova variante de $\beta$-Glu em $H$. rigidifolia; estas variantes foram detectadas com a utilização dos substratos fluorogênicos fosfato de umbeliferona e 4-metil-umbeliferil- $\beta$ D-glucopiranosideo, respectivamente.

\section{DISCUSSÃO}

A semelhança na resolução dos zimogramas em amostras liofilizadas, centrifugadas a $15.000 \mathrm{~g}$ à temperatura de $4^{\circ} \mathrm{C}$ e em amostras centrifugadas a $2.500 \mathrm{~g}$ à temperatura ambiente se explica pela alta densidade do material foliar no extrato, facilitando sua precipitação, mesmo sob centrifugação a baixa rotação.

Não foram observadas alterações expressivas nas isoenzimas presentes em folíolos em diferentes estádios da 
ontogenia foliar $\left(B_{2}, B_{3}\right.$ e $\left.C\right)$. A semelhança nos padrões isoenzimáticos entre os estádios fenológicos $\mathrm{B}_{2}, \mathrm{~B}_{3}$ e C está de acordo com Soleille (1984) que discorre sobre os foliolos como um aparelho enzimático pouco variável, permitindo comparações jovem/adulto. Lebrun \& Chevallier (1988) propõem o estádio fenológico B como o ideal para a coleta de foliolos, pois as antocianinas estão formadas e a atividade enzimática é estável. Os resultados descritos neste trabalho mostram, entretanto, que a coleta dos folíolos pode ser realizada tanto nos estádios $\mathrm{B}_{2} / \mathrm{B}_{3}$ como em $\mathrm{C}$.

A liofilização dos foliolos foi eficaz para as enzimas que apresentaram boa resolução, com exceção de Got e Est; a atividade destas enzimas não resiste à estocagem dos foliolos liofilizados, devendo, neste caso, ser examinada em extratos de folíolos frescos recém-preparados.

As esterases, peroxidases e polifenoloxidases atuam em diversos substratos, apresentando, usualmente, um grau elevado de polimorfismo, sendo, dessa forma, utilizadas como marcadores. Podem exibir padrões ou atividades diferentes na presença de substratos diversos fornecidos à reação de revelação (Alfenas et al., 1991 ).

Foram identificadas nove regiões de atividade esterásica, provavelmente determinadas por nove locos esterásicos distintos. Chevallier (1988), entretanto, identificou somente quatro locos codificadores de esterases. A utilização de substratos fluorogênicos permitiu, portanto, a detecção de um número bem maior de locos do que os reportados na literatura. A região reportada por Soleille (1984) como exibindo variação, provavelmente, corresponde à esterase-7 descrita neste trabalho. A verificação da ocorrência da esterase6 e de sua variação somente se tornou possivel neste trabalho graças à utilização do substrato fluorogênico diacetato de fluoresceina. Atividade de esterase-4, revelada com palmitato de umbeliferona, um éster de ácido graxo de cadeia longa, não foi observada em todas as amostras analisadas. Esta ausência de atividade pode ser atribuída às diferenças de estádio fenológico dos foliolos de clones diferentes.

A semelhança nos padrões encontrados para esterase-7 e endopeptidases indica que esta esterase apresenta atividade proteolitica; portanto, é possivel que a esterase- 6 atue "in vivo" como uma protease. Até o momento, estas enzimas eram consideradas como proteinas distintas.

As variantes de Acp em $H$. nitida e de $\beta$-Glu em $H$. rigidifolia são descritas neste trabalho pela primeira vez. Como no caso das esterases, a utilização de substratos fluorogênicos tornou possível a detecção destas variantes eletroforéticas. Soleille (1984), Chevallier (1984) e Chevallier et al. (1988) encontraram quatro alelos determinando os fenótipos de Acp. Os alelos 1 e 3 são raros, ocorrendo em populações do estado de Rondônia; o alelo 3 foi detectado também em amostras do Acre (Chevallier, 1984).

De acordo com nossos achados, o perfil eletroforético de Got exibiu três regiões de atividade, possivelmente 
codificadas por três locos distintos. Dados da literatura (Soleille, 1984; Chevallier et al., 1988) reportam apenas a existència de dois locos codificadores das múltiplas formas da transaminase glutâmica-oxaloacética. De modo semelhante ao verificado para os achados referentes às esterases, à Acp e à $\beta$-Glu, a identificação destes três locos foi possivel devido à utilização de uma mistura de revelação mais sensível que, diferentemente da utilizada por aqueles autores, baseia-se na reoxidação do NADH como indicativo da atividade enzimática (ver Harris \& Hopkinson, 1976).

Paiva et al. (1993), analisando duas populações de seringueira do Acre, conseguiu boa resolução para a região Lap-2, constatando a ocorrência de quatro alelos neste loco. Entretanto, neste trabalho, bem como em Soleille (1984), a Lap-2 não apresentou resolução satisfatória.

Os padrões apresentados por Mdh-1 e 6Pgdh, expressos na repetição do mesmo fenótipo em duas regiões distintas de atividade, sugerem a formação de isoenzimas secundárias a partir dos produtos primários dos genes envolvidos. Apesar do padrão mais complexo, as condições de migração utilizadas neste trabalho permitiram maior facilidade na interpretação dos zimogramas.

Este trabalho contribui, assim, para demonstrar que extratos de foliolos em diferentes estádios fenológicos, provenientes de portaenxertos com diferentes origens genéticas, submetidos a diferentes condições de preparo e centrifugação, tornam possível o estudo dos padrões eletroforéticos de várias enzimas (Acp, Idh, Pgm, $\beta$-Glu, Adh, 6Pgdh, Pgi, Lap-1, Mdh, Skdh, Est e Got). A utilização de substratos fluorogênicos e a padronização de outros sistemas tamponantes tornou possivel a visualização de novos fenótipos para algumas das enzimas estudadas (esterases e transaminases glutâmicaoxaloacética) ou uma maior facilidade na interpretação dos zimogramas (malato desidrogenase e 6-fosfogliconato desidrogenase), bem como a detecção de novas variantes eletroforéticas de fosfatase ácida e de $\beta$-glucosidade. Estes achados evidenciam, assim, a importância de se buscar as melhores condições para que a variação genética nos locos estudados possa ser adequadamente estimada.

\section{AGRADECIMENTOS}

Os autores agradecem ao Prof. Dr. José Dias da Costa, ao pesquisador Dr. Paulo de Souza Gonçalves e aos Técnicos de Laboratório Ricardo Pessôa Rebello e Elisabete Barreto Beira pela ajuda durante este trabalho.

\section{Bibliografia Citada}

Alfenas, A.C.; Peter, I.; Brune, W.; Passador, G.C. 1991. Eletroforese de proteinas e isoenzimas de fungos e esséncias florestais. Viçosa, Editora da Universidade Federal de Viçosa, 242 p.

Chevallier, M.H. 1984. Preliminary studies of genetic variability of the germplasm from 1981 Amazon prospection. In: Collogue Exploitation, Physiologie et Amélioration de l'Hevea, Montpellier, France, 1984. IRRDB. p. 453-462.

Chevallier, M.H. 1988. Genetic variability of Hevea brasiliensis germplasm using 
isozyme markers. J. Rubb. Nat.Rubb. Res., 3(1): 42-53.

Chevallier, M.H.; Soleille, B.; Nicolas, D. 1985. Polymorphisme enzymatique ef variabilité génétique de l Hévéa. Caoutchoucs et Plastiques, 652:83-87.

Chevallier, M.H.; Lebrun, P; Normand, P. , 1988. Approach to the genetic variability of germplasm using enzymatic markers. Colloque Exploitation, Physiologie et Amélioration de l'Hevea, Montpellier, France, 1984. IRRDB. p, 365-376.

Dean, W. 1989. A luta pela borracha no Brasil: um estudo de história ecológica. Sào Paulo, Nobel, $286 \mathrm{p}$.

Hallé, F; Oldeman, R.A.; Tomlinson P.B. 1978. Tropical Trees and Forests. Berlin, Springer-Verlag, $441 \mathrm{p}$.

Harris, H.; Hopkinson, D.A. 1976, Handbook of Enzyme Electrophoresis in Human Genetics. Amsterdan, Elsevier.
Institute des Recherches Sur Le Caoutchouc. 1981. Laboratoire d' Électrophorèse. Rapport Annuel 1981. Paris. IRCA. p. 33-37.

LeBrun, P.; Chevallier, M.H. 1988. Starch and Polyacrylamide Gel Electrophoresis of Hevea brasiliensis: a Laboratory Manual. Montpellier. IRCA-CIRAD Publ., 44 p.

Paiva, J.R. de ; Kageyama, P.Y: Vencowsky, R. 1993. Outcrossing rates and inbreeding coeficients in rubber trees ( Hevea brasiliensis Willd ex. Ar. de Juss. Mueller Arg.) Brazil. J. Genét., 16(4):1003-1012.

Soleille, B. 1984. Étude de la variabilité enzymatique chez Hevea brasiliensis. Paris. Tese de Doutoramento, Université de Paris-Sud Centre D' Orsay, 163 p. 